\title{
DESIGN OF AN ACTIVE SEAT SUSPENSION FOR A PASSENGER VEHICLE
}

\author{
M. Hoić ${ }^{\otimes}$, N. Kranjčević, Z. Herold and M. Kostelac \\ University of Zagreb, Croatia \\ $\triangle$ matija.hoic@fsb.hr
}

\section{Abstract}

The design of an active seat suspension for a mid-class passenger vehicle based on the given set of requirements is considered a combination of four subsystems; the carrier, the actuator, the spring, and the damper. The design of the former two is considered through the 10 and 16 concepts for each, respectively. Two overall designs are proposed for further development. One based on a dual ScottRussell mechanism and one based on Sarrus mechanism. The first one is evaluated to have high stiffness, the second to be more cost-effective. The detailed design of the first concept is presented.

Keywords: active seat suspension, assessment, 3D modelling, new product development, design analysis

\section{Introduction}

An increasing number of people spend significant amount of time sitting in a car which results in an increased occurrence of health problems which include lower back pain, neck pain, neuropathy, cardiovascular disease, digestion disorders, and even cancer (Fan et al. (2020), Zhao and Wang (2019)). The leading overall cause for the health problems of the passengers is the occurrence of low excitation vibrations with frequencies between 0.5 to $10 \mathrm{~Hz}$ (Bai et al. (2019), Heidarian et al. (2019)) in all directions. For a typical passenger vehicle, dominantly adverse effects are caused by the 5 to 8 $\mathrm{Hz}$ vertical vibrations, which correspond with the natural frequency of the human organs (Heidarian et al. (2019)). However, for off-road vehicles, vibrations in the horizontal direction may become dominant (Kim et al. (2018)). It has been demonstrated that the reduction of vibrations acting on the driver by means of a seat suspension can reduce negative influence on the health (Liu et al. (2019), Deng et al. (2019)) as well as improve driving comfort and safety.

One additional positive impact of the high-performance suspension system is expected in the case of autonomous vehicles where the driver becomes a passenger. Instead of driving, the driver can now use the time spent in the vehicle for work, which may have positive impact on the economy (Clements and Kockelman (2017)), or leisure.

Three types of suspensions are suggested; passive, semi-active, and active (Heidarian et al. (2019), Deng et al. (2019)). Passive seat suspensions are quite commonly used for vibration suppression in heavy-duty vehicles; however, most commonly they cannot isolate low-frequency vibrations (Heidarian et al. (2019), Ning et al. (2017), Zhao et al. (2019)). Semi-active suspensions are reported to have the best ratio of cost to performance (Heidarian et al. (2019), Deng et al. (2019), Ning et al. (2019), Kou et al. (2017)). Active suspensions are assessed to have the best performance, albeit at high cost, complexity, 
and energy consumption (Heidarian et al. (2019), Deng et al. (2019), Ning et al. (2018)). It should be noted that energy regenerative seat suspension may reduce the energy requirements, especially for electric vehicles (Ning et al. (2018)). An additional improvement in the performance of the active seat suspension can be expected for the autonomous vehicles using the road preview provided by the sensory equipment for improvement in suspension control (Hrovat et al. (2019)).

The goal of the research presented in the paper is to propose a design of an active seat suspension suitable for a mid-class passenger vehicle, i.e., the proposed design must be characterized by (i) successful damping of the broad range of vertical vibrations, (ii) low height design which can be integrated in a typical midclass passenger vehicle, (iii) high lateral stiffness to prevent horizontal vibrations, and (iv) low cost. It is worth mentioning that the initial prototype would be installed on the seat shaker test rig used for investigations on the subjectively perceived ride comfort (Cvok et al., 2020). The goal would be to investigate the possibility of improvement of ride comfort employing active seat suspension vs. the seat without suspension. Paper presents the results of the research through the following structure of the sections. The second section elaborates on the requirements on the active set suspension. Concepts of the solutions and the choice of the best solution are covered in the third section. Necessary calculations of the chosen concept solution as well as the design solution are presented in Section 4.

\section{Design requirements on the active seat suspension design}

For the disengaged actuator, the seat and the passenger lean against the spring (or springs) with a total estimated mass of approximately $200 \mathrm{~kg}$. The actuator is placed in parallel to the spring and variates the force of the spring in either direction. In order to minimize the variation of the spring force for the target vertical displacement, target spring stiffness should be as low as possible. The mechanism would benefit from high efficiency and zero clearance from the standpoint of energy consumption and control quality during the reversal of motion direction. At a minimum, the efficiency must be high enough to prevent self-locking which enables the suspension to act as a semi-active suspension in the case of the motor shutdown. Similarly, zero clearance would be beneficial; the system may be functional even with a small clearance, the control quality would be affected, and some additional noises may occur.

Several additional features are recognized as necessary for a successful operation of the system. The design should include the bumpers at the extreme displacements to prevent damage to the mechanism in the cases of overshoot. Dampers should be detachable to enable experiments with different damper designs on the prototype version of the system and possibly installation of dampers with different damping characteristics depending on the type of the vehicle and possibly the preference of the driver. The manual locking mechanism should enable the driver to use the seat as rigid seat without suspension. The initial position should be adjustable to suit different height and weight of the passenger. Low cost and a possibility to fit within the volume currently occupied by the rigid connector of the seat to the chassis are required for the solution to be suitable for the regular in-vehicle application.

Design requirements on the design of the active sear suspension are summarized in Table 1. It can be noted that the requirements are similar or somewhat higher compared to the characteristics of the setups presented in Gan et al. (2015) and Ning et al. (2016).

Table 1. Main requirements on the seat suspension design

\begin{tabular}{|c|c|}
\hline Spring stiffness of $10 \mathrm{~N} / \mathrm{mm}$ & Natural frequency $>50 \mathrm{~Hz}$ \\
\hline Spring static load of $2000 \mathrm{~N}$ & No (minimum) clearance \\
\hline Maximum actuator force $1000 \mathrm{~N}$ & Bumpers at the extreme positions \\
\hline Maximum speed of $0.5 \mathrm{~m} / \mathrm{s}$ & Detachable damper \\
\hline Maximum acceleration of $1 \mathrm{~g}$ & Manual locking mechanism \\
\hline Vertical displacement of $\pm 40 \mathrm{~mm}$ & $\begin{array}{c}\text { Increased actuator displacement OR manual setup of the } \\
\text { initial position }\end{array}$ \\
\hline High efficiency (no self-locking mandatory) & Low cost \\
\hline High lateral stiffness & Dimensions of $450 \times 450 \times 140 \mathrm{~mm}$ (length $\times$ width $\times$ height) \\
\hline
\end{tabular}




\section{Analysis and evaluation of a seat suspension concepts}

The target suspension system can be divided into 4 (mechanical) subsystems; (i) carrier structure, (ii) source of force (the actuator), (iii) spring, and (iv) damper. Initial analysis places focus on the first two subsystems (carrier and actuator) due to (i) their primary influence on the cost / complexity of suspension system, (ii) the requirement on their position between the seat and the chassis, (iii) and the expected high portion of the available volume which these subsystems require. The later will be added later during more detailed design.

\subsection{Concepts of the seat carrier structure}

A total of 10 concepts of the seat carrier structure has been considered (see Figure 1). The summary of the estimations on the main characteristics of the overviewed concepts is given in Table 2 .

Table 2. Assessment of the overviewed seat carrier structure concepts

\begin{tabular}{|c|c|c|c|c|c|c|c|}
\hline 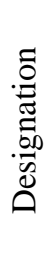 & 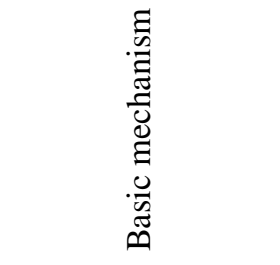 & 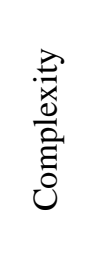 & $\vec{y}$ & $\begin{array}{l}\frac{7}{60} \\
\frac{00}{2} \\
\frac{1}{3} \\
0 \\
0\end{array}$ & 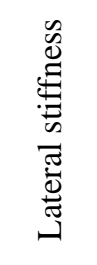 & 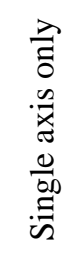 & Used in \\
\hline A & Linear guides & Low & High & No & Mid & Yes & $\begin{array}{c}\text { Bai et al. (2019), Kieneke et al. (2013), } \\
\text { Gunston et al. (2004), } \\
\text { Deng et al. (2019), Gan et al. (2015) }\end{array}$ \\
\hline b & Lever + spring & Low & Low & Yes & High & No & None found \\
\hline $\mathrm{c}$ & Elastic carrier & High & Mid & Yes & Low & No & Begin et al. (2018) \\
\hline $\mathrm{d}$ & Scissor type & $\begin{array}{l}\text { Low } \\
\text {-to- } \\
\text { mid }\end{array}$ & High & Yes & High & Yes & $\begin{array}{l}\text { Liu et al. (2019), Heidarian et al. (2019), } \\
\text { Ning et al. (2019), Ning et al. (2018), } \\
\text { Zhao et al. (2018), Ning et al. (2017), } \\
\text { Kou et al. (2017), Ning et al. (2016) }\end{array}$ \\
\hline $\mathrm{e}$ & Dual Scott-Russel & mid & High & Yes & High & Yes & None found \\
\hline $\mathrm{f}$ & Parallel levers & Mid & Low & Yes & High & No & $\begin{array}{c}\text { Kim et al. (2018), } \\
\text { Bai et al. (2016), } \\
\text { Holtz and van Niekerk (2010) }\end{array}$ \\
\hline $\mathrm{g}$ & $\begin{array}{c}\text { Dual parallel } \\
\text { levers + slider }\end{array}$ & High & $\begin{array}{l}\text { Mid-to- } \\
\text { high }\end{array}$ & Yes & High & Yes & None found \\
\hline $\mathrm{h}$ & $\begin{array}{c}\text { Bellow } \\
\text { (Accordion) }\end{array}$ & High & Low & Yes & $\begin{array}{l}\text { Mid- } \\
\text { to- } \\
\text { high }\end{array}$ & Yes & None found \\
\hline $\mathrm{i}$ & $\begin{array}{c}\text { Diamond-shaped } \\
\text { levers }\end{array}$ & Mid & $\begin{array}{l}\text { Mid-to- } \\
\text { high }\end{array}$ & Yes & High & Yes & None found \\
\hline $\mathrm{j}$ & Sarrus & Low & Low & Yes & Mid & Yes & None found \\
\hline
\end{tabular}

More straightforward and cost-effective solutions are considered as better as a measure of suitability for mass production. The low height is required to enable the application of the system on a typical mid-class passenger vehicle as an option for a regular seat over fixed connection. The mechanism should have high stiffness and generate displacement in a vertical direction only to prevent lateral displacement and vibrations.

The following concepts are considered as potential solutions; the Scissor mechanism, Dual ScottRussel mechanism, and the Sarrus mechanism. The Scissor type is a somewhat favored solution (see Table 2) with favorable mechanical characteristics. However, to prevent vertical clearance, the wheels (see Figure 1d) must be replaced with linear guides resulting in a significant cost increase. Similar reasoning (apart from the popularity of the solution) can be provided for the dual Scott-Russell 
mechanism. Sarrus mechanism appears to be quite promising solution with the exclusion of stiffness. The assessment on the stiffness relates to numerous joints present in the design; actual stiffness depends on the detailed design solution and cannot be precisely determined at this stage.
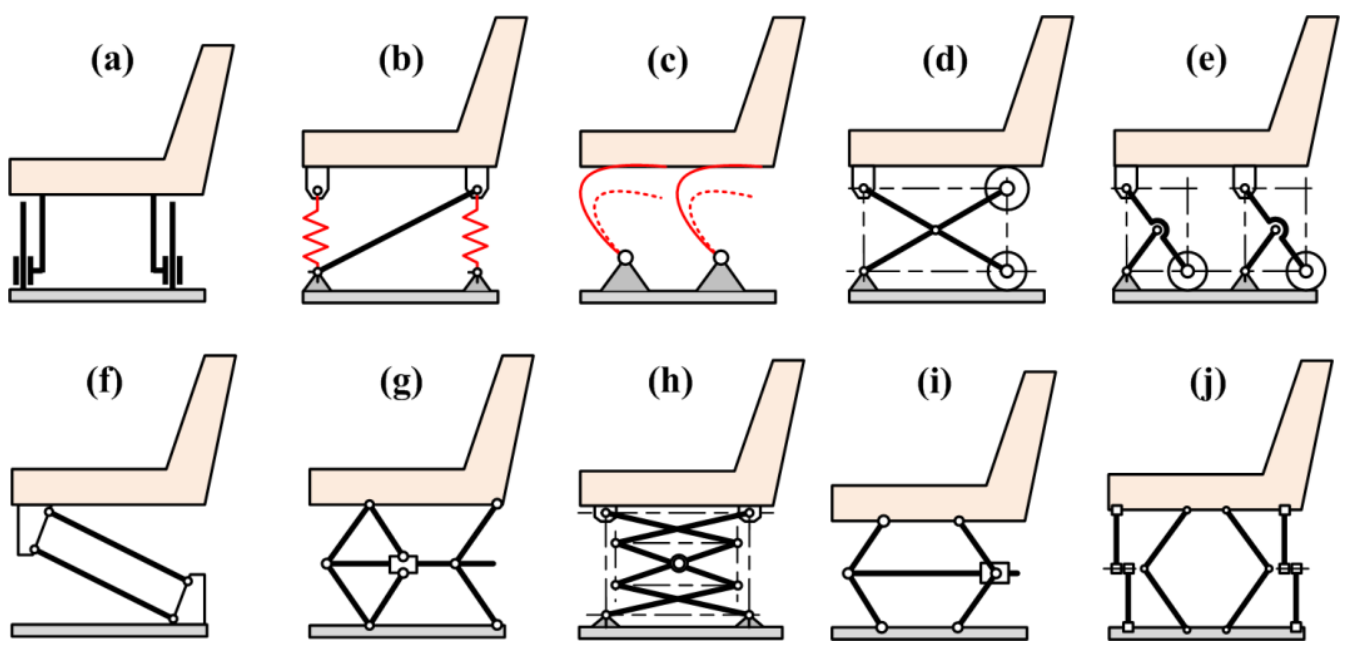

Figure 1. Schematics of the considered seat carrier structure concepts

\subsection{Concepts of the seat actuator}

A total of 16 concepts of the active seat suspension actuator is proposed (see Figure 2 and Table 3 ). All concepts are based on the rotational electrical motor as a primary source of mechanical power as a cost-effective solution compared to e.g. linear electrical motors (as presented in Maas (2004)).
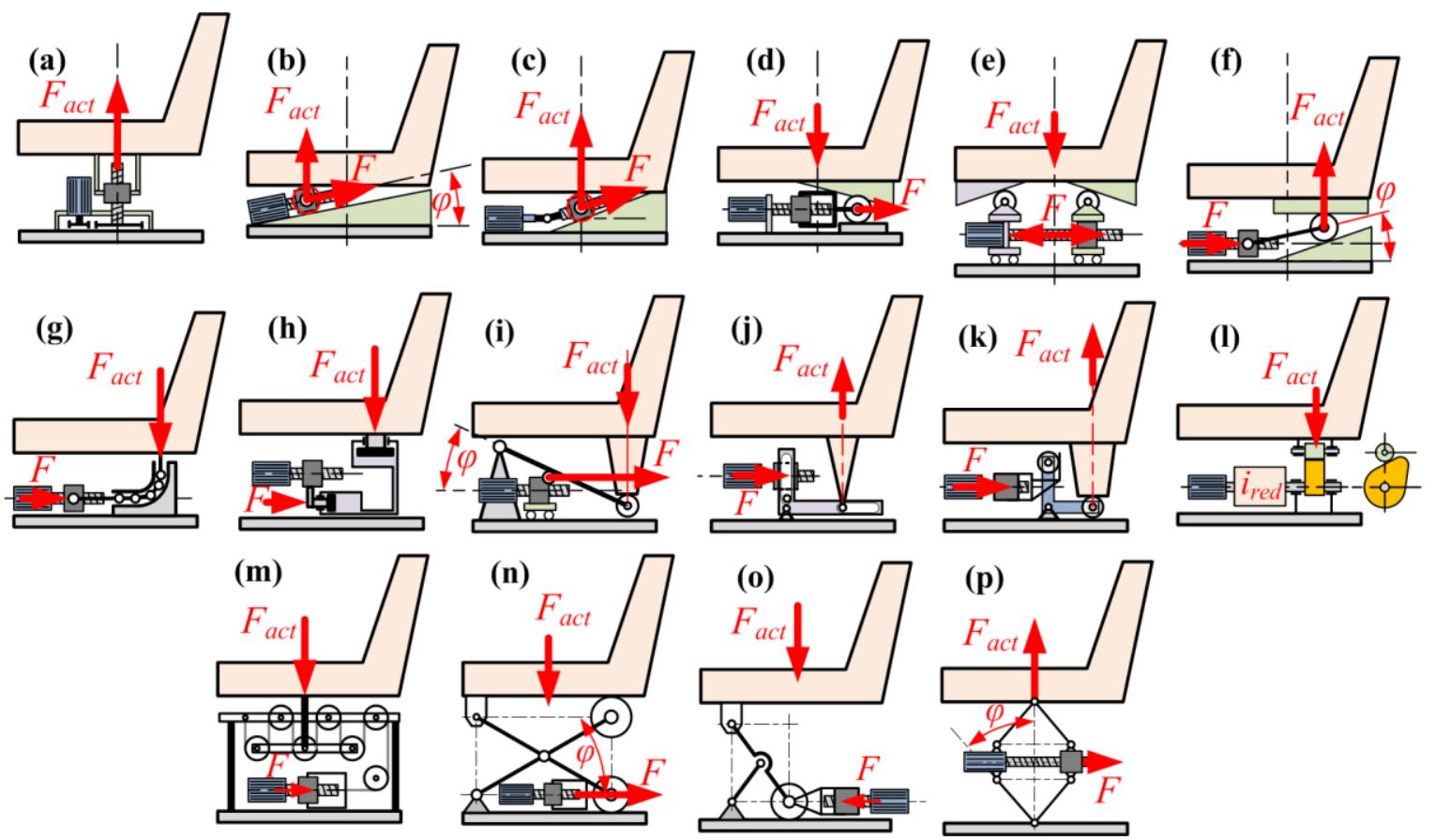

Figure 2. Schematics of the considered seat suspension actuator

Concepts are evaluated through seven characteristics (see Table 3): (i) Complexity (related also to cost to some extent), (ii) Low height/volume, (iii) Efficiency, (iv) Rigidity, (v) Bi-directional actuation, (vi) Spindle (F) to actuator (Fact) force ratio, (vii) and generation of load in a single axis only. The bidirectional direction relates to the capability of the design as presented to be able to both push and pull. Actuator force/torque to force acting on the seat ratio is preferably constant (not necessarily equal to one) from the standpoint of dimensions and cost as the system must be designed for maximum load. 
If the actuator generates force in more than one axis, it generates additional load resulting in the increased dimensions of the system.

Table 3. Overview of the main characteristics of the considered seat actuator concepts

\begin{tabular}{|c|c|c|c|c|c|c|c|c|}
\hline 竞 & 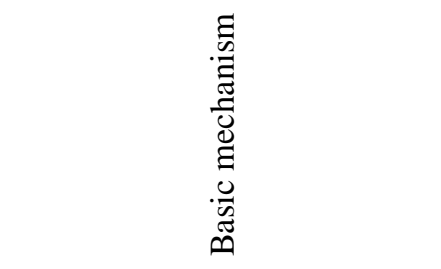 & 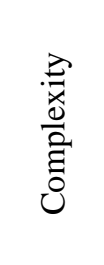 & 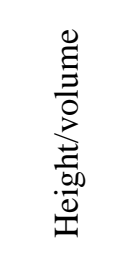 & 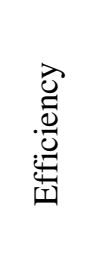 & 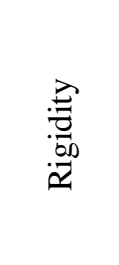 & 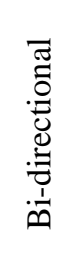 & $\underbrace{\frac{\vec{U}}{I}}_{I}$ & 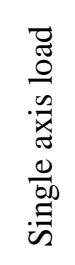 \\
\hline $\mathrm{a}$ & Gears/tooth belt + spindle & Low & High & High & $\begin{array}{l}\text { Mid to } \\
\text { high }\end{array}$ & Yes & 1 & Yes \\
\hline $\mathrm{b}$ & Spindle on a ramp & Mid & Low & High & Rigid & No & Const. & Yes \\
\hline $\mathrm{c}$ & $\begin{array}{c}\text { Spindle on a ramp + Angled } \\
\text { shaft }\end{array}$ & High & Low & High & Rigid & No & Const. & Yes \\
\hline $\mathrm{d}$ & Spindle + Fixed ramp & $\begin{array}{l}\text { Fairly } \\
\text { low }\end{array}$ & $\begin{array}{l}\text { Low to } \\
\text { mid }\end{array}$ & High & Rigid & No & Const. & No \\
\hline $\mathrm{e}$ & Double spindle + ramp & High & $\begin{array}{l}\text { Low to } \\
\text { mid }\end{array}$ & High & $\begin{array}{l}\text { Mid- } \\
\text { to-high }\end{array}$ & No & Const. & Yes \\
\hline $\mathrm{f}$ & Spindle + Lever + Fixed ramp & Low & Low & High & $\begin{array}{l}\text { Mid- } \\
\text { to-high }\end{array}$ & No & Non-const. & Yes \\
\hline g & Spindle + Chain & High & Mid & Mid & Mid & Yes & 1 & Yes \\
\hline $\mathrm{h}$ & $\begin{array}{l}\text { Spindle }+ \text { Hydrostatic } \\
\text { transmission }\end{array}$ & High & Low & Mid & Low & No & Const. & Yes \\
\hline $\mathrm{i}$ & Spindle + Rotating cantilever & Low & Low & High & High & No & Non-const. & Yes \\
\hline $\mathrm{j}$ & Spindle $+90^{\circ}$ lever & Mid & Low & High & High & Yes & Const. & No \\
\hline $\mathrm{k}$ & Spindle $+90^{\circ}$ lever + wheels & Low & Low & High & High & No & Const. & Yes \\
\hline 1 & Reducer + Camshaft & High & Low & Mid & High & No & Non-const. & No \\
\hline $\mathrm{m}$ & Spindle + Pulley mechanism & Low & Low & High & $\begin{array}{l}\text { Low- } \\
\text { to-mid }\end{array}$ & No & Const. & Yes \\
\hline $\mathrm{n}$ & Spindle + Scissor mechanism & Low & Low & High & High & Yes & $F=\frac{F_{a c t}}{\tan \varphi}$ & Yes \\
\hline o & Spindle + Scott-Russel & Low & Low & High & High & Yes & $F=\frac{F_{a c t}}{\tan \varphi}$ & Yes \\
\hline $\mathrm{p}$ & $\begin{array}{l}\text { Spindle + Diamond-shaped } \\
\text { levers }\end{array}$ & Low & Low & High & High & Yes & $F=F_{a c t} \tan \varphi$ & Yes \\
\hline
\end{tabular}

\subsection{Choice of the overall concept}

Two overall concepts (see Figure 3) are suggested for further development. The first includes combine carrier and actuator both based on the dual Scott-Russell mechanism (see Figure 3a). Based on the similarity with the scissor mechanism, this concept is estimated to have the best mechanical properties concerning stiffness and efficiency, albeit at the expense of high costs due to linear guides and non-constant force ratio (i.e. it may not be suitable for mass production). It is suggested that this concept is recommended to be the first one to be developed and built in the existing active seat shaker test rig, thus providing the benchmark for future more cost-effective designs. It may be argued that a similar solution based on the scissor mechanism can be proposed, like existing solution. For this case, the tan function and the low height to width ratio would result in a noticeable variation in the ratio of the forces, unlike refenced solutions where width to height ratio of the developed system is closer to one. For the dual Sarus mechanism, specific mechanisms can be 
designed with levers operating around the $45^{\circ}$ positions, i.e. dual Sarrus mechanism can be designed with each Sarrus mechanism to have height to width ratio close to one.
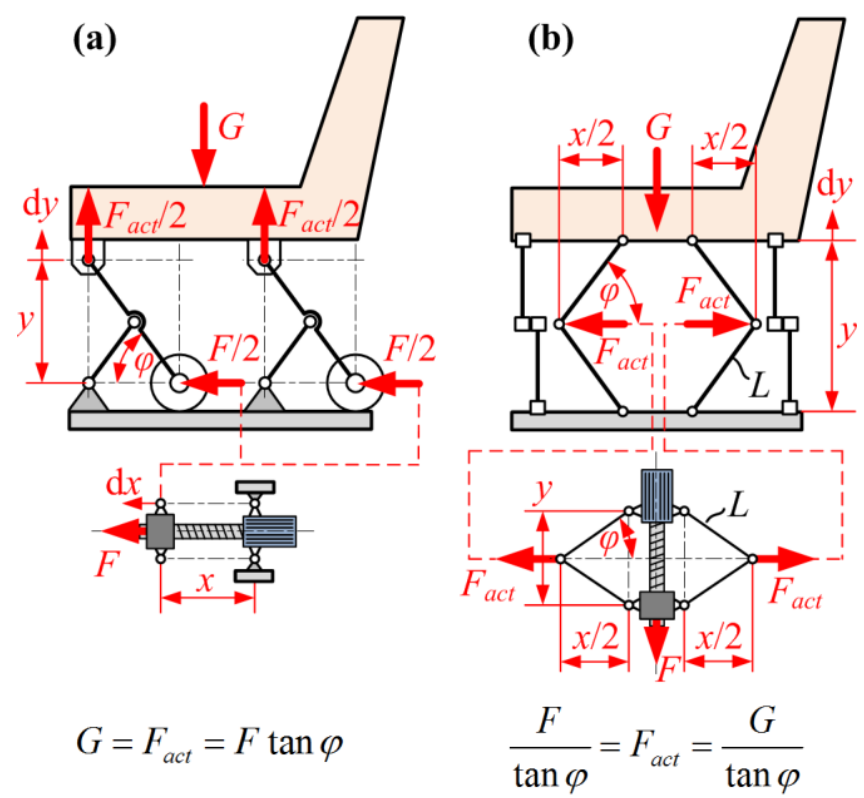

Figure 3. Chosen overall concepts of the active seat suspension

The second suggested concept is based on the Sarrus mechanism carrier and a diamond-shaped lever actuator (see Figure 3b). The concept does not include the linear guides, and the combination of the diamond and Sarrus mechanism results in a constant spindle to seat force ratio. This concept is estimated to be the potential candidate for mass production solution due to low cost, albeit at the expense of somewhat lower stiffness because of the significant number of joints. Consequently, this concept is suggested as a second one to be developed to explore capabilities of a potentially viable cost-effective design. The apparent absence of known applications suggests that this mechanism presents a possibility of a novel actuator design. However, it may be argued that the same absence of application implies that the Sarrus mechanism is not suitable for a given application.

It may be summarized that the Scott-Russell mechanism-based solution is estimated to have advanced mechanical performance properties while it is not cost effective while the Sarrus mechanism-based solution is suitable as a basis for a low cost mass produced system while the performance may not be satisfactory.

\section{Proposed hardware design for the test rig solution}

The following section describes the design of the active seat suspension based on the Scott-Russell mechanism to be used in combination with the existing active seat shaker test rig. The existing shaker test rig will emulate the vibrations transferred from the chassis of the vehicle onto the seat while the active suspension will try to dampen these vibrations. Several test subjects will be subjected to the same scenarios of vertical vibrations with and without active suspension to investigate the capabilities of the active seat suspension to improve the ride comfort.

\subsection{General calculations of the system}

General calculations of the proposed test rig include the choice of the spindle, the servomotor, linear guides (see Table 4), and the design of the mechanical spring. Mechanism introduces non-linear relations between the displacement, speed, acceleration, and force on the seat $\left(y, v_{\mathrm{G}}, a_{\mathrm{G}}, G\right)$ and corresponding parameters on the spindle nut $(x, v, a, F)$ :

$$
\frac{y}{x}=\frac{v_{G}}{v}=\frac{a_{G}}{a}=\frac{G}{F}=\tan \varphi
$$


It is worth noting that the ratio between the corresponding parameters on the nut and the rotational displacement $(\alpha)$, speed $(\omega)$, and acceleration $(\varepsilon)$ as well as the torque on servomotor $(M)$ equals the transfer ratio of the spindle $(i)$ which is a function of the pitch of the spindle $\left(i=1 / P_{\mathrm{h}}\right)$. Maximum spindle acceleration of $4000 \mathrm{rad} / \mathrm{s}^{2}$ (Ball screw catalogue) necessitated the choice of maximum feasible length of the main lever $(L=130 \mathrm{~mm})$ to minimize the lever angle in order to maximize the feasible acceleration. For the pitch value of $P_{\mathrm{h}}=10 \mathrm{~mm}$, acceleration in excess of $1 \mathrm{~g}$ is possible for displacement between -4 and $+2 \mathrm{~cm}$ and drops to $0.8 \mathrm{~g}$ at $+4 \mathrm{~cm}$. Spindle models with a pitch of $20 \mathrm{~mm}$ would enable the required acceleration over the entire span of displacement. However, due to increased dimensions, friction in the system would also increase (double) to values which would undermine the functionality of the system over the entire range of displacement. Thus, the spindle with a $10 \mathrm{~mm}$ pitch was chosen as a better solution.

Long term exposure to maximum target force on the seat is not expected. Thus, a servomotor whose maximum torque can generate maximum required force on the seat and accelerate all the masses of the suspension system is estimated to be appropriate. Based on the chosen spindle, required motor speed must exceed $2500 \mathrm{rpm}$. Several models are a viable solution; the chosen model (see Table 4) was selected due to lowest mass and dimensions.

Table 4. Main chosen subsystems

\begin{tabular}{|c|c|c|}
\hline $\begin{array}{c}\text { Type of } \\
\text { component }\end{array}$ & Model & Main characteristics \\
\hline Spindle & SKF SND/BND 16x10 R & Diameter $16 \mathrm{~mm}$, Pitch 10 mm, Dynamic load $10.7 \mathrm{kN}$ \\
\hline Servomotor & Siemens 1FT7034-\#AK7\# & $\begin{array}{c}\text { Nominal power of } 880 \mathrm{~W}, \text { nominal speed of } 6000 \mathrm{rpm}, \\
\text { dimension } 72 \times 72 \times 189 \mathrm{~mm}\end{array}$ \\
\hline $\begin{array}{c}\text { Linear } \\
\text { guides }\end{array}$ & Bosch Rexroth KWD 015 SNS N1 & Dynamic load $10 \mathrm{kN}$, speeds up to $5 \mathrm{~m} / \mathrm{s}$ \\
\hline
\end{tabular}

The system is considered as a two-mass vibration system with the seat and the motor inertia on each side and the ball screw in the middle representing the spring element (see Figure 4). Levers and the spindle are positioned in the serial and parallel connection with the spindle, respectively. Due to high stiffness of the levers, and the low stiffness of the spring, they were not included in the initial calculation. Note that in the case when the spindle is self-locked, the vibration could not be transferred from the seat to the motor inertia, i.e., the system would act as a single mass system.

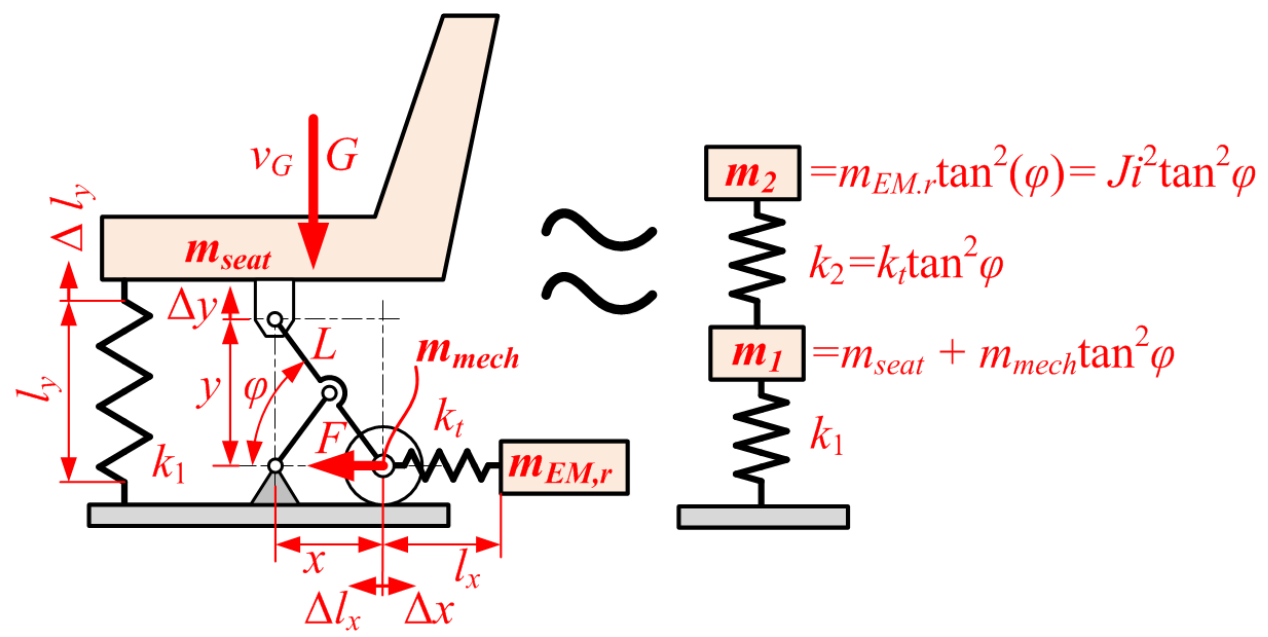

Figure 4. Vibration model of the seat with the suspension

Natural frequencies of the system thus equal:

$$
f_{n}=\frac{1}{2 \pi} \sqrt{\frac{1}{2}\left[B \pm \sqrt{B^{2}-C}\right]} ; \quad B=\frac{k_{1}}{m_{1}}+\frac{k_{2}}{m_{2}}\left(1+\frac{m_{2}}{m_{1}}\right) ; \quad C=\frac{4 k_{1} k_{2}}{m_{1} m_{2}}
$$


Where masses in the equivalent system the spindle stiffness transferred to the seat axis equal:

$$
m_{1}=m_{\text {seat }}+m_{\text {mech }} \tan ^{2} \varphi ; \quad m_{2}=m_{E M, r} \tan ^{2} \varphi=J i^{2} \tan ^{2} \varphi ; \quad k_{2}=k_{t} \tan ^{2} \varphi
$$

For the chosen motor, spindle, and length of the levers, the natural frequency was calculated to be over $200 \mathrm{~Hz}$ for all positions. It is estimated that the more detailed calculations which is possible for more detailed design will result in somewhat smaller natural frequency, however, still well in excess of the minimum requirement of $50 \mathrm{~Hz}$.

Linear guides based on the linear ball bearing design are chosen based on the load limit. The smallest available model was chosen as it surpasses the requirement on the vertical load. The same model can be obtained without preload or with a 2, 8 , or $13 \%$ of nominal load preload. Albeit smaller preload results in more favourable smaller friction losses, a preload of $2 \%$ was chosen since it was reasoned that the difference in friction losses compared to the non-preloaded version is small while preload is expected to avoid clearance in the system and lower the variation in friction losses.

\subsection{Mechanical design and integrations with existing Shaker test rig}

The designed active suspension system is planned to be placed between the top plate of the shaker and the seat in the place of the existing frame, which connects the seat to the vehicle chassis (see Figure 5a and $5 \mathrm{~b}$ ). Design solution includes symmetrical top and bottom plate; both planned to be attachable both to the test rig and the seat (i.e. the system can be installed upside down) to enable insights into possible influence of mass distribution on the behaviour of the system.

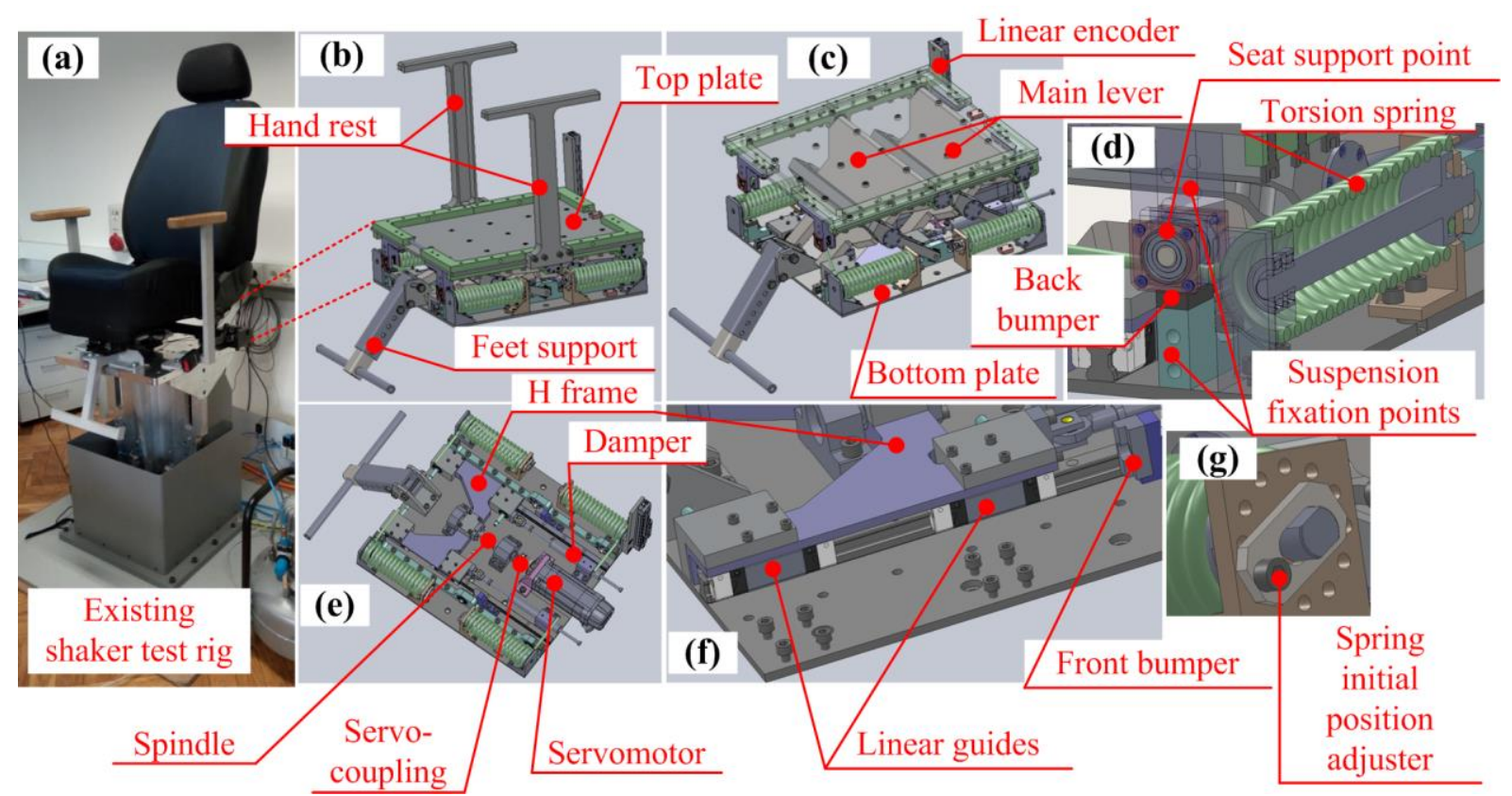

Figure 5. 3D CAD model of the active seat suspension solution based on a dual Scott-Russell mechanism

The actuator subsystem consisting of a servomotor, servo coupling, and the spindle is placed in the central plane and generates linear motion in the horizontal plane (see Figure 5e). The nut of the spindle is connected to the $\mathrm{H}$ shaped frame, which runs on the linear guides (see Figure 5f) and acts as a support for the main (long) mechanism levers.

To satisfy the load capacity of the full weight of the seat and the passenger and have small stiffness, the springs must have both broad cross-section and length. Torsional springs are chosen as they can be fitted within the available volume and have a small number of additional parts thus minimizing complexity and friction (see Figure 5d). The seat support points act against the levers of the torsional springs, which generate the torque loading the spring. The spring is wound around the central shaft 
whose initial circumferential position can be adjusted thus enabling the adjustments of the initial vertical position of the seat (see Figure $5 \mathrm{~g}$ ).

Passive dampers are placed parallel to the spindle and connected to the $\mathrm{H}$ frame; they can be detached or replaced with a different model (see Figure 5e). The active suspension system can be locked by connecting the fixed and moveable parts of the mechanism via appropriate plates on the front and the backside of the test rig (see Figure 5d). Two sets of bumpers are placed at the extreme positions of the mechanism (see Figure 5d and f).

Shaker test rig is equipped with the accelerometer and a linear encoder that measure acceleration and the displacement of the shaker upper plate, and consequently the seat due to rigid connection. An additional accelerometer is placed at the top plate of the active suspension system, and an additional linear encoder is placed between the upper and the lower plate of the suspension mechanism (see Figure $5 \mathrm{c}$ ), thus enabling the measurement of relative acceleration and displacement between the shaker and the seat.

\section{Conclusion}

To improve the comfort and minimize adverse health influence of long-term exposure to vertical vehicle vibrations, an active suspension seat based on a dual Scott-Russell mechanism has been proposed in this paper. The prototype is designed to be installed onto the existing shaker test rig to investigate the possibilities of comfort improvement utilizing active seat suspension vs. rigid seat frame. The basic mechanical principle is chosen as a solution for the prototype based on high estimated stiffness, which enables high performance. The results of the experiments conducted using this suspension system may thus serve as a benchmark for other design solutions. The higher cost is not relevant herein since the prototype is only intended to be made for laboratory purposes.

It is argued that the chosen principle may not be suitable as a basis for a commercial version since the necessity of linear guides limits the possibilities for cost reduction. Solution based on a Sarrus mechanism whose mechanism includes only rotary joints is thus proposed. The prototype of this solution is suggested to be designed afterward and compared against the solution based on the ScottRussell mechanism by conducting the same series of experiments on the same shaker test rig.

\section{Acknowledgment}

It is gratefully acknowledged that this research has been supported by the Ford Motor Company. The authors would like to thank Prof. Joško Deur and Mag. Ivan Cvok for the specifications of the design requirements and constructive suggestions.

\section{References}

Begin, M.-A. et al. (2018), "Experimental Assessment of a Controlled Slippage Magnetorheological Actuator for Active Seat Suspensions", IEEE/ASME Transactions on Mechatronics, Vol. 23 No. 4, pp. 1800-1810. https://doi.org/10.1109/TMECH.2018.2836351

Bai, X.X., Jiang, P. and Qian, L. (2016), "Integrated semi-active seat suspension for both longitudinal and vertical vibration isolation", Journal of Intelligent Material Systems and Structures, Vol. 28 No. 8, pp. 1-14. https://doi.org/10.1177/1045389X16666179

Bai, X.X.F. and Yang, S. (2019), "Hybrid controller of magnetorheological semi-active seat suspension system for both shock and vibration mitigation”, Journal of Intelligent Material Systems and Structures, Vol. 30 No. 11, pp. 1613-1628. https://doi.org/10.1177/1045389X19844009

Clements, L.M. and Kockelman, K.M. (2017), "Economic effects of automated vehicles", Transportation Research Record, Vol. 2606, pp. 106-114. https://doi.org/10.3141/2606-14

Cvok, I. et al. (2020), "A shaker rig-based testing of perceived ride comfort for various configurations of active suspensions", submitted for review to Vehicle System Dynamics.

Deng, H. et al. (2019), "Design and verification of a seat suspension with variable stiffness and damping", Smart Materials and Structures, Vol. 28 No. 6, pp. 1-12. https://doi.org/10.1088/1361-665X/ab18d4

Fan, X. et al. (2020), "Review of the Research on Car Seating Comfort", In: Rebelo, F. and Soares, M. (Eds.), Advances in Ergonomics in Design, Springer, Basel, pp. 296-304. https://doi.org/10.1007/978-3-030-20227-9_27

Gan, Z., Hillis, A.J. and Darling, D. (2015), “Adaptive control of an active seat for occupant vibration reduction", Journal of Sound and Vibration, Vol. 349, pp. 39-55. https://dx.doi.org/10.1016/j.jsv.2015.03.050 
Gunston, T.P., Rebelle, J. and Griffin, M.J. (2004), “A comparison of two methods of simulating seat suspension dynamic performance”, Journal of Sound and Vibration, Vol. 278, pp. 117-134. https://doi.org/10.1016/ j.jsv.2003.09.063

Heidarian, A. and Wang, X. (2019), "Review on Seat Suspension System Technology Development", Applied Sciences, Vol. 9 No. 14. https://doi.org/10.3390/app9142834

Holtz, M.W. and van Niekerk, J.L. (2010), "Modelling and design of a novel air-spring for a suspension seat", Journal of Sound and Vibration, Vol. 329, pp. 4354-4366. https://doi.org/10.1016/j.jsv.2010.04.017

Hrovat, D., Tseng, H.E. and Deur, J. (2019), "Optimal Vehicle Suspensions: A System-Level study of potential benefits and limitations", In: Lugner, P. (Ed.), Vehicle Dynamics of Modern Passenger Cars, Springer International Publishing, Cham, pp. 109-204.

Kieneke, R., Graf, C. and Maas, J. (2013), “Active Seat Suspension with Two Degrees of Freedom for Military Vehicles", IFAC Proceedings Volumes, 6th IFAC Symposium on Mechatronic Systems, April 10-12, Vol. 46 No. 5, 2013, Hangzhou, China. https://doi.org/10.3182/20130410-3-CN-2034.00085

Kim, J.H., Marin, L.S. and Dennerlein, J.T. (2018), "Evaluation of commercially available seat suspensions to reduce whole body vibration exposures in mining heavy equipment vehicle operators", Applied Ergonomics, Vol. 71, pp. 78-86. https://doi.org/10.1016/j.apergo.2018.04.003

Kou, F. et al. (2017), "Characteristics research on energy-harvest semi-active seat suspension with magnetorheological damper”, 2017 IEEE 3rd Information Technology and Mechatronics Engineering Conference (ITOEC), Vol. 28 No. 8, pp. 1036-1049. https://doi.org/10.1177/1045389X16666179

Liu, P. et al. (2019), "Torque response characteristics of a controllable electromagnetic damper for seat suspension vibration control", Mechanical Systems and Signal Processing, Vol. 133, pp. 1-17. https://doi.org/10.1016/j.ymssp.2019.07.019.

Maas, J. (2004), “Active Seat Suspension for Passenger Cars”, IFAC Proceedings Volumes, Vol. 37 No. 14, pp. 313-318. https://doi.org/10.1016/S1474-6670(17)31122-9

Ning, D. et al. (2016), “An active seat suspension design for vibration control of heavy-duty vehicles", Journal of Low Frequency Noise Vibration and Active Control, Vol. 35 No. 4, pp. 264-278. https://doi.org/10. $1177 / 0263092316676389$

Ning, D. et al. (2017), "Disturbance observer based Takagi-Sugeno fuzzy control for an active seat suspension", Mechanical Systems and Signal Processing, Vol. 93, pp. 515-530, http://dx.doi.org/10.1016/j.ymssp. 2017.02.029

Zhao, L. et al. (2018), "Modelling and validation of a seat suspension with rubber spring for off-road vehicles", Journal of Vibration and Control, Vol. 24 No. 18, pp. 1-12. https://doi.org/10.1177/1077546317719348

Ning, D. et al. (2018), "Vibration control of an energy regenerative seat suspension with variable external resistance", Mechanical Systems and Signal Processing, Vol. 106, pp. 94-113. https://doi.org/10.1016/j. ymssp.2017.12.036

Ning, D. et al. (2019), "An electromagnetic variable inertance device for seat suspension vibration control", Mechanical Systems and Signal Processing, Vol. 133, pp. 1-19. https://doi.org/10.1016/j.ymssp.2019. 106259

Zhao, Y. and Wang, X. (2019), "A Review of Low-Frequency Active Vibration Control of Seat Suspension Systems”, Applied Sciences, Vol. 9 No. 16. https://doi.org/10.3390/app9163326

Ball screw catalog, Available at: https://www.skf.com/binary/21-149715/Precision-rolled-ball-screws---6971_1EN.pdf. 